Die mittleren Oerter geben die Differenzen $(B-R)$ :

I. März I $7: \mathrm{d} \lambda=+0.8 \mathrm{~d} \beta=+0.9$

II. März 25: $\mathrm{d} \lambda=-\mathrm{I} .4 \mathrm{~d} \beta=-0.9$.

Eine nachträglich verglichene Hamburger Beobachtung vom 3. April giebt:

$$
\mathrm{d} \lambda=-1 " \mathrm{I} \quad \mathrm{d} \beta=+3.2 \text {. }
$$

Heliocentrische Aequatorealcoordinaten:

$$
\begin{aligned}
& x=[9.9229637] r \cdot \sin \left(v+349^{\circ} 1^{\prime} 5^{\prime \prime} .82\right) \\
& y=[9.9997808] r \cdot \sin \left(v+2575^{\circ} 34.28\right) \\
& z=\left[9.73^{8} 3^{217}\right] r \cdot \sin \left(v+345333^{\circ} .33\right)
\end{aligned}
$$

Ephemeride für $r 2^{\text {h }}$ M. Z. Berlin.

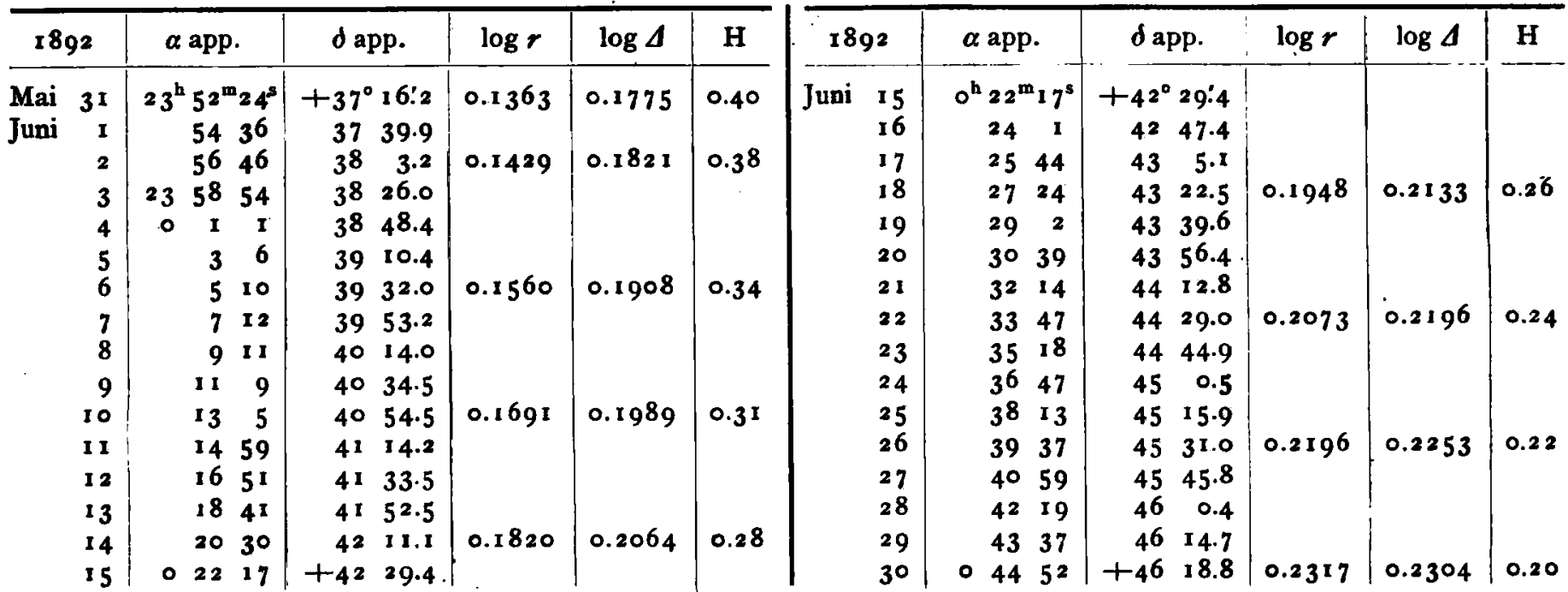

Einheit von $\mathbf{H}$ ist die Helligkeit zur Zeit der Entdeckung des Cometen.

Berlin, Kgl. Recheninstitut, I892 April I3.

A. Berberich.

\title{
Aus einem Schreiben von Herrn Prof. Wolf in Zürich
}

betr. Nr. 79 seiner Astronomischen Mittheilungen.

Die soeben in der Vierteljahrschrift der Naturforschenden Gesellschaft in Zürich erschienene Nr. 79 meiner "Astronomischen Mittheilungen enthält ausser der Bestimmung einer Variationsformel für Tiflis, der Fixirung des letzten Sonnenflecken-Minimums auf

$$
\text { I } 889.6
$$

und einer Fortsetzung des Sammlungs-Verzeichnisses der Züricher Sternwarte, eine längere Reihe von Auszügen aus
Briefen von Emile Gautier und Urbain Leverrier, welche über das Verhältniss dieser beiden Männer, die Geschichte der Entdeckung Neptuns, und den oft verkannten Charakter von Leverrier viele wichtige Aufschlüsse geben und daher ein allgemeines Interesse haben dürften.

Für die Freunde meines neuen Handbuches füge ich bei, dass der dritte Halbband desselben demnächst er. scheinen wird.

Zürich 1892 März 20.

Rud. Wolf.

\section{Aufforderung betr. Beobachtungen des Cometen 1890 II.}

Herr Cand. E. Strömgren in Lund beabsichtigt die Bahn dieses Cometen zu berechnen und bittet um Mittheilung etwa noch nicht publicirter Beobachtungen.

Lund I892 März 22.

Folke Engström.

\section{In halt:}

Zu Nr. 3088. A. Berberich. Die Bahnneigungen der kleinen Planeten. 265. - R. Luther. Kreismikrometer-Beobachtungen von kleinen Planeten am Siebenfüsser zu Düsseldorf. 267. - N. von Konkoly. Versuch einer vorläutigen geographischen Längenbestimmung. 27I. - K. Bohlin. Elemente des Planeten (315) Constantia. 273. - A. Berberich. Elemente und Ephemeriden der Planeten (324) und (326). 275. A. Berberich. Ephemeriden der Planeten (325) und (329). 275. - A. Berberich. Ephemeride des Planeten (304) Olga. 277. E. Millosevich. Orbita ellittica del pianetinó (306) Unitas. 277. - D. Klumpke. Beobachtungen des Planeten (325) (Wolf März 4). 277. - A. Berberich. Elemente und Ephemeride des Cometen 1892 ... (Swift März 6). 277. - Aus einem Schreiben von Herrn Prof. Wolf in Zürich. 279. - Aufforderung betr. Beobachtungen des Cometen 1890 II. 279. 